\title{
A STUDY TO ASSESS KNOWLEDGE , ATTITUDE AND PRACTICE OF ADVERSE DRUG REACTION REPORTING AMONG PHYSICIANS IN A TERTIARY CARE HOSPITAL
}

Jyotirmoy Adhikary, Basavaraj Bhandare, Adarsh. E, Satyanarayana.V

\author{
1. Post Graduate. Department of Pharmacology, Rajarajeswari Medical College \& Hospital, Bangalore. \\ 2. Professor \& HOD. Department of Pharmacology, Rajarajeswari Medical College \& Hospital, Bangalore. \\ 3. Professor \& HOD. Department of Pediatrics, Rajarajeswari Medical College \& Hospital, Bangalore. \\ 4. Professor. Department of Pharmacology, Rajarajeswari Medical College \& Hospital, Bangalore.
}

\section{CORRESPONDING AUTHOR}

Dr. Jyotirmoy Adhikary, Department of Pharmacology, Rajarajeswari Medical College \& Hospital, Kambipura, Mysore road, Bangalore - 560074 .

E-mail: joeadhikary@gmail.com Ph: 00919435122196

ABSTRACT: BACKGROUND: Adverse drug reaction (ADR) monitoring and reporting activity is in its infancy in India. Spontaneous reporting of adverse drug reactions (ADR) is an important method in pharmacovigilance, but under-reporting is a major limitation. AIMS: Physicians being frontline caregivers this study was conducted to assess the knowledge, attitude and practice (KAP) of ADR reporting among physicians in a tertiary care hospital. SETTING AND DESIGN: This cross sectional, questionnaire based study was carried out amongst all the physicians working at Rajarajeswari Medical College \& hospital, Bangalore over a period of 1 month. MATERIALS AND METHODS: A questionnaire was prepared after a initial pilot study and was distributed among all the physicians. For every Physician 30 minutes was given to fill up the questionnaire. Later on the filled questionnaires were collected and analyzed as per the study objectives. RESULTS: A questionnaire was distributed to 189 physicians, but only 122 returned the questionnaire (response rate of $\mathbf{7 0 . 9 \%}$ ). This study revealed inadequate knowledge and poor practice of ADR reporting. Though $\mathbf{5 6 . 8 \%}$ physician felt that they encountered ADRs, only $22.1 \%$ had actually ever reported an ADR. The most common reasons of under reporting were lack of time(34.5\%), followed by lack of knowledge of reporting procedure $(30.4 \%)$. But the physicians showed positive attitude towards ADR reporting. $\mathbf{9 5 . 0 \%}$ felt that that ADR reporting is necessary and $\mathbf{7 9 . 5 \%}$ supported for establishing ADR monitoring centre in every hospital. Most of the physicians (95.9\%) suggested that continuous medical education and training on ADR reporting is necessary for overcoming the problem of underreporting of ADRs. CONCLUSION: The study results revealed the existence of underreporting of ADRs, but also the willingness of clinicians to be trained in ADR reporting and contributing to the pharmacovigilance programme. It is desirable to initiate workshops and training programs on ADR reporting to overcome the problem of underreporting

KEY WORDS : Adverse drug reaction (ADR ) , ADR Reporting , Pharmacovigilance .

INTRODUCTION: Adverse drug reactions (ADRs) are global problems of major concern and considered as one among the leading causes of morbidity and mortality. The epidemiological importance of ADR is justified by its high prevalence rate- they cause from $3 \%$ to $6 \%$ of hospital 
admissions at any age, and up to $24 \%$ in the elderly population; they rank fifth among all causes of death and represent from 5 to $10 \%$ of hospital costs and so is a great cause of concern to the medical profession [1]. In order to identify the offending drugs causing ADRs, several countries have initiated pharmacovigilance programs in the recent past. In India, ADR reporting and the pharmacovigilance program is in the stage of infancy and thus there is a need to promote the program among the healthcare professionals [2]. The primary source of information for pharmacovigilance is from spontaneous reporting by health care professionals. Under-reporting of ADRs is a major problem affecting pharmacovigilance programme of India. Because of under reporting, Indian drug regulators are very much dependent on data and advice from other countries.

Findings from studies conducted abroad revealed ADR reporting to be linked to the knowledge, attitude and practices (KAPs) of the healthcare professionals [3,4]. So in order to improve an existing pharmacovigilance program, there is an urgent need to improve healthcare professionals' KAP. Prior to carrying out any intervention, it is necessary to evaluate the baseline KAP of the healthcare professionals regarding ADR monitoring and pharmacovigilance so that the intervention can be targeted based on the specific findings. Evaluating their KAP can help in developing strategies to improve the program in the hospital. Similarly, this information can be useful for the other pharmacovigilance centers in the country. Hence, the present study was carried out with objectives of assessing the knowledge, attitude and practice of physicians regarding spontaneous ADR reporting and pharmacovigilance; identification for reasons of under reporting of ADRs; suggesting methods for improvement in current ADR reporting system and pharmacovigilance program.

MATERIALS \& METHODS: This cross sectional, questionnaire based study was carried out amongst all the physicians working at Rajarajeswari Medical College \& hospital , Bangalore over a period of 1 months from November 2012 to December 2012 to assess the KAP of the physician towards ADR reporting. Before the start of the study, approval from the Institutional Ethical Committee was obtained. A questionnaire was prepared after a initial pilot study and was distributed among all the physicians. Physicians were contacted directly in their department and the questionnaires were distributed. For every Physician 30 minutes was given to fill up the questionnaire. Any clarification needed in understanding the questionnaire was provided. Later on the filled questionnaires were collected and analyzed as per the study objectives.

STUDY TO0L: A questionnaire composed of 25 questions was prepared after an earlier pilot study conducted in our hospital. First part of the questionnaire was designed to get the demographic information of the participant physician. The remaining questions were designed to evaluate knowledge (10 questions), Attitude towards ADR reporting (5 questions ), practice of adverse drug reaction reporting ( 7 questions), two open ended questions were designed to know the encouraging and discouraging factors for ADR reporting, and after that one open ended question was designed to get suggestions from physicians for improvement of ADR reporting .

Questions on knowledge revealed : definition of ADR, pharmacovigilance etc ; awareness of regional pharmacovigilance center ;Regulatory body responsible for monitoring of ADRs in India ; regarding person who can report ADR etc. 
Questions on attitude revealed awareness of responsibility towards ADR reporting as a physician, opinion about establishing ADR monitoring centre in every hospital, importance of pharmacovigilance teaching programme to health care professionals etc.

Questions on practice revealed reporting of ADRs by physician, approach to prevent adverse drug reactions, encouraging and discouraging factor for reporting ADR etc. The last question was an open question to get suggestions for improvement of ADR reporting.

RESULTS: Out of 189 physicians approached to participate in study, 122 physicians completed and returned the questionnaire, giving response rate of $\mathbf{7 0 . 9} \%$. Out of 122 respondents, 77 (63.1\%) were postgraduates and 45 (36.8\%) were undergraduates. $45(36.8 \%)$ physicians had working experience of 0 -5 yrs , 44 (36.1\%) had 5 - 15 years , 26 (21.3\%) had 15 - 25 years and $7(0.1 \%)$ physicians had working experience of more than 25 years .

\section{KNOWLEDGE OF THE PHYSICIANS OF ADR REPORTING :}

- About 81(66.3\%) and 71(58.1\%) physicians stated the correct definition of the ADR and pharmacovigilance respectively.

- 75 participants $(\mathbf{6 1 . 4 \% )}$ ) knew the address of the regional pharmacovigilance center.

- 63 participants (51.6\%) knew that Central Drug Standard Control Organization is the regulatory body responsible for monitoring of ADRs in India.

- 79 participants (64.7\%) reported that they knew the concept of serious adverse event.

- 62 participants $(\mathbf{5 0 . 8 \%})$ knew that CDSCO form is used in India to report ADRs.

- 83 participants (68.0\%) knew that all health professionals could report ADR as per CDSCO guidelines.

- 31 participants $(\mathbf{2 5 . 4} \%)$ preferred reporting ADR to National Pharmacovigilance Center 35 (28.6\%) prefer to regional pharmacovigilance center, 26 (21.3\%) to hospital pharmacovigilance center and $21(\mathbf{1 7 . 2 \% )}$ to regulatory authority of the hospital .

\section{ATTITUDE OF THE PHYSICIANS TOWARDS ADR REPORTING :}

- 116 (95.0\%) physicians felt that that ADR reporting is necessary as a professional obligation.

- 97 (79.5\%) participants supported for establishing ADR monitoring centre in every hospital.

- $112(\mathbf{9 1 . 8 \% )}$ stated that ADR monitoring and pharmacovigilance should be taught in details to healthcare professionals

- 102 (83.6 \%) felts that existing ADR reporting and monitoring system would improve the patient care.

- 65 participant (53.2\%) felt that ADR reporting should be mandatory, while 41 (33.6\%) felt that it should be voluntary, $\mathbf{1 6}$ (13.1\%) felt it should be remunerated .

\section{PRACTICE OF THE PHYSICIANS OF ADR REPORTING :}

- Most of the participants 69 (56.8\%) felt that they encounter ADR while 52(43.2\%) expressed that they rarely encounter an ADR.

- $\mathbf{5 5}(\mathbf{4 5 . 0 \% )}$ had read articles on prevention of ADRs. 
- Only 26 (21.3\%) participants stated that they had trained on Pharmacovigilance and Adverse Drug Reaction reporting.

- Only 46 (37.7\%) physicians were aware of the Pharmacovigilance center at our hospital.

- $98(\mathbf{8 0 . 3 \% )}$ followed approach to prevent adverse drug reactions

- 65 (53.2\%) ever prevented an adverse drug reaction from occurring

\section{ENCOURAGING FACTORS FOR REPORTING ADRS}

The respondents were encouraged to report ADRs if the reaction was

- Serious - 90 (73.7\%),

- Unusual -74 (60.6\%) in nature.

Other factors that would influence ADR reporting include if

- The reaction was to a new product - 67 (55.6\%),

- Certainly that the reaction was an ADR- 49 (40.4\%),

- The reaction was well recognised for a particular drug- 43 (35.4\%).

\section{DISCOURAGING FACTORS FOR REPORTING ADRS}

- $\quad$ Lack of time to report ADRs - 42 (34.5\%)

- Do not know how to report ADRs -37 (30.4\%)

- Difficult to decide whether ADR has occurred or not -31 (25.4\%)

- A single unreported case may not affect ADR database-13 (10.6\%)

- Mild adverse effect- 10 (8.4 \%)

- No reward when reporting ADRs-12 (9.8\%)

- Well known reactions- 9 (7.3\%)

- Worry to be accused for causing ADRs to patients- 8 (6.5\%)

\section{SUGGESTED METHODS OF IMPROVING ADR REPORTING:}

- Continuous medical education, training and refresher study for health care professionals on Pharmacovigilance and ADRs reporting - 117 (95.9\%)

- Creating awareness among health professionals to identify and notify adverse events $\mathbf{- 8 3}$ (68.0\%)

- Reminders and increased awareness from the ADR Monitoring Committee - $81(66.3 \%)$

- Encouragement from the hospital authorities- 61 (50.0\%)

- Having an ADR monitoring specialist in every department -57(46.7\%)

- Encouraging on-line or telephone reporting- 55(45.0\%)

- Associating ADR reporting with rewards- 35 (28.6\%)

DISCUSSION: The World Health Organization defines adverse drug reactions (ADRs) as 'a reaction which is noxious and unintended and which occurs at doses normally used in humans for prevention, diagnosis or therapy of disease, or for the modification of physiological functions. ADRs are important public health problem and one of the leading causes of morbidity 
and mortality [5]. In order to identify the offending drugs causing ADRs, several countries have initiated pharmacovigilance programs in the recent past[2]. To improve the ADR reporting activities in India, the Ministry of Health and Family Welfare had initiated the National Pharmacovigilance Program (NPP) on January 2005 which was further revived in July 2010 [6,7].This program is overseen by Central Drugs Standard Control Organization (CDSCO), New Delhi [8].

Spontaneous and voluntary reporting system is an integral component of pharmacovigilance program [9,10]. Despite the acceptance of spontaneous reports as a critical and crucial method for ADR reporting, globally under-reporting of ADRs is a major problem and India is not an exception to it. In one Indian study[11] incidence of ADR was found only $2.8 \%$. One major reason for this was underreporting, similar to that observed in another Indian study[12] . According to Murphy et.al[13] as many as 35\% of hospitalized patients experienced an ADR during their hospital stay but most of them are unreported.

This study has shown inadequate knowledge of physicians about ADR reporting and pharmacovigilance. In our study About $66.3 \%$ and $58 \%$ of the physicians stated the correct definition of the ADR and pharmacovigilance respectively which was found to be lower than other Indian studies[8,14].

In our study $25.4 \%$ preferred reporting ADRs to National Pharmacovigilance Center, 28.6\% prefered to Regional Pharmacovigilance Center, $21.3 \%$ to Hospital Pharmacovigilance Center and $17.2 \%$ to regulatory authority of the hospital. As per NPP (National Pharmacovigilance Programme, ADRs should be reported to national or regional centers; it can be sent through institutional pharmacovigilance center [6, 7 ]. But in our study only $21.3 \%$ preferred to report to hospital pharmacovigilance center. This might be because only $37.7 \%$ participants were found to be aware of the hospital pharmacovigilance center.

The existing system of ADR monitoring in many countries rely upon the spontaneous reporting of health professionals as a mean source for information. But the limitations of this system is underreporting, biases, estimation of population exposure and report quality[15]. Apart from health care professionals, patients or consumers have also the right to report their experiences and suffering as a result of these adverse effects[16]. Reports of suspected ADRs from consumers have been accepted by regulatory authorities in the U.S. since 1993, in Sweden since 1978, and in several European countries since 2003[17].

Some of the significant roles of consumer reporting are:1) Consumers become active players in drug safety with respect to pharmacovigilance and can actively contribute through an integrated and efficient reporting system; 2) With consumer reporting, ADRs will be detected earlier and more number of ADRs would be reported and thereby we can overcome the problems of underreporting of current system; 3) it will promote consumer rights [18].

A review published on the reporting of ADRs by patients indicated that patient reporting of suspected ADRs has more potential benefits than drawbacks. ADRs that were not previously reported by health professionals were picked up by direct patient ADR reports [19]. Therefore, there is a need to develop a proactive pharmacovigilance structure in India for direct patient reporting[20].

In our study, most of the participants were found to have positive attitude towards ADR reporting. $79.5 \%$ participants supported for establishing ADR monitoring centre in every hospital and $91.8 \%$ stated that ADR monitoring and pharmacovigilance should be taught in details to healthcare professionals. 
Currently, reporting of ADRs by physicians in India is a voluntary activity. But in our study $53.2 \%$ participants felt that ADR reporting should be mandatory. Mandatory reporting of ADRs will not only enhance the quantum of reports, but it will also be useful in developing the culture of reporting among physicians[20].

In our study, Most the respondents were encouraged to report ADRs if only the reaction was serious $(73.7 \%)$ which was similar to one study [21]. Hence, the awareness about the need for reporting all the adverse drug reactions should be improved in our hospital.

Though $95.0 \%$ physicians felt that that ADR reporting is professional obligation, only 22.1\% had actually reported an ADR. The most common reasons of under reporting we have found in this study were 1] Lack of time to report ADRs (34.5\% ); 2] Do not know how and whom to report ADRs (30.4\%); 3] Difficult to decide whether ADR has occurred or not $25.8 \%$ ) and these findings were similar with one Indian study[22].

Many factors are reported to be associated with under-reporting of ADRs by health care professionals [23]. For many different reasons (such as lack of knowledge, lack of awareness of pharmacovigilance systems, heavy work load, hesitation in making the correct decision), health care professionals do not report ADRs as frequently as expected [24]. Inman[25] has summarized reasons for under-reporting as the 'seven deadly sins' and his description of the 'sins' include: ignorance ('I am unsure how to report'), diffidence ('I may appear foolish about reporting a suspected ADR'), fear ('I may expose myself to legal liability by reporting an ADR'), lethargy ('I am too busy to report ADRs'),guilt ('I am reluctant to admit I may have caused harm'), ambition ('I would rather collect cases and publish them') and complacency ('only safe drugs are marketed').

One of the better means of overcoming under-reporting is to increase the KAP of the healthcare professional regarding ADR monitoring and pharmacovigilance programs ${ }^{[2]}$. Educational intervention has been shown to improve ADR reporting in Portugal[26] and Rhode Island in the USA[27]. Education and training on spontaneous ADR reporting is very necessary among the doctors. In our study only $21.3 \%$ of respondent had ever received such training. But they have showed positive attitude for education and training of ADR reporting and pharmacovigilance. 95.9\% supported that continuous medical education, training and refresher courses on ADR reporting and pharmacovigilance can improve the current ADR reporting system and will be helpful in overcoming the problems of under reporting. This certainly shows that the physicians are willing to improve their knowledge of ADR reporting and increase their participation in pharmacovigilance programme. The other most recommended methods by the physicians for improvement in ADR reporting are creating awareness among health professionals to identify and notify adverse events (68.4\%) and reminders and increased awareness from the ADR Monitoring Committee (64.4\%).

Limitations of the study include- the results were only of a single hospital and those inherent to questionnaire-based studies such as subjective response and recall bias. The study findings can be generalized if further extended to other hospitals in the country.

CONCLUSION: The healthcare professionals of our hospital has relatively better attitude but limited knowledge and practice towards ADR reporting and pharmacovigilance. The majority of the healthcare professionals felt ADR monitoring to be important, but only a few had ever reported an ADR to the pharmacovigilance center. The study results revealed the existence of underreporting of ADRs, but also the willingness of clinicians to be trained in ADR reporting and contributing to the pharmacovigilance programme. It is desirable to initiate workshops and 
training programs on ADR reporting to overcome the problem of underreporting; and ADR reporting should be considered as an integral part of the clinical activities by the health care providers.

\section{REFERRENCE:}

1. Srinivasan R, Ramya G. Adverse drug reaction causality assessment. International Journal of Research in Pharmacy and Chemistry 2011 ; 1(3): 606-11

2. Palaian S, Ibrahim MI, Mishra P. Health professionals' knowledge, attitude and practices towards pharmacovigilance in Nepal . Pharmacy Practice 2011; 9(4):228-235

3. Aziz Z, Siang TC, Badarudin NS. Reporting of adverse drug reactions: predictors of under-reporting in Malaysia. Pharmacoepidemiol Drug Saf 2007; 16(2):223-228

4. Herdeiro MT, Figueiras A, Polónia J, Gestal-Otero JJ. Physicians' attitudes and adverse drug reaction reporting: a case-control study in Portugal . Drug Saf 2005 ; 28(9):825833

5. John LJ , Arifulla M , Cheriathu J et.al . Reporting of Adverse Drug Reactions: a study among Clinicians , Journal of Applied Pharmaceutical Science 2012; 02 (06): 135-139

6. Biswas $P$, Biswas AK. Setting standards for proactive pharmacovigilance in India: The way forward. Indian J Pharmacol 2007 ; 39 (3) :124- 128.

7. Gupta YK. Ensuring Patient Safety - Launching the New Pharmacovigilance Programme of India . Pharma Times 2010; 42 (08):21-6

8. Amrita P, Singh SP . Status of spontaneous reporting of adverse drug reaction by physicians in Delhi . Indian Journal of Pharmacy Practice 2011; 4 (2) : 29 - 36, ()

9. 9. Waller PC. Making the most of spontaneous adverse drug reaction reporting . Basic Clin Pharmacol Toxicol 2006 ; 98 (3):320-323

10. Vallano A, Cereza G, Pedròs C, Agustí A, Danés I, Aguilera C, et al. Obstacles and solutions for spontaneous reporting of adverse drug reactions in the hospital. Br J Clin Pharmacol 2005 ; 60 (6):653-658

11. Rao PG, Archana B, Jose J. Implementation and results of an adverse drug reaction reporting programme at an Indian teaching hospital. Indian J Pharmacol 2006 ; 38(4):293-4

12. 12. Ramesh M, Pandit J, Parthasarathi G, Adverse drug reactions in a South Indian hospital-their severity and cost involved, Pharmacoepidemiol Drug Safety 2003, 12(8):687-92

13. 13. Murphy BM, Frigo LC . Development, implementation, and results of a successful multidisciplinary adverse drug reaction reporting program in a university teaching hospital . Hosp Pharm 1993; 28 (12):1199-204

14. 14. Muraraiah S, Rajarathna K. Sreedhar D et.al . A questionnaire study to assess the knowledge, attitude and practice of Pharmacovigilance in a paediatric tertiary care centre ,

15. J. Chem. Pharm. Res. 2011; 3(6):416-42 Goldman SA . Limitation and strengths of spontaneous reports data. Clinical Therapeutics $1998 ; 20$ (3) : c40-c44

16. Van Grootheest AC, de Jong-van den Berg L . Review: Patients' role in reporting adverse drug reactions . Exp Opin Drug Saf 2004; 3(4): 363-8

17. Aagaard L, Nielsen LH, Hansen EH . Consumer reporting of adverse drug reactions: a retrospective analysis of the Danish adverse drug reaction database from 2004 to 2006 . Drug Safety 2009 ; 32(11):1067-74 
18. Ahmed A M, Izham I M , Subhas P. The Importance of the Consumer Pharmacovigilance System in Developing Countries: A Case of Malaysia . Journal of Clinical and Diagnostic Research $2010 ; 4$ (4) : 2929-2935

19. Blenkinsopp A, Wilkie $P$, Wang M, Routledge PA. Patient reporting of suspected adverse drug reactions: a review of published literature and international experience . Br J Clin Pharmacol 2007; 63(2):148-56

20. Rishi RK, Patil RK et.al . Opinion of physician towards adverse drug reaction reporting, results of pilot study. Journal of community nutrition and health 2012; 1 ( 1 ): $25-29$

21. Oshikoya K A, Awobusuyi J 0 . Perceptions of doctors to adverse drug reaction reporting in a teaching hospital in Lagos, Nigeria . BMC Clinical Pharmacology 2009 ; 9:14 doi:10.1186/1472-6904-9-14 .

22. Rishi RK, Patel RK, Bhandari A . Under Reporting of ADRs by Medical Practitioners in India - Results of Pilot Study ,. Adv Pharmacoepidem Drug Safety 2012; 1 (3 ) doi:10.4172/2167-1052.1000112

23. Lopez-Gonzalez E, Herdeiro MT, Figueiras A . Determinants of under-reporting of adverse drug reactions: a systematic review. Drug Saf 2009; 32(1):19-31

24. Nazl Sencan, Meryem Altınkaynak, Irmak Ferah .The knowledge and attitudes of physicians and nurses towards adverse event reporting and the effect of pharmacovigilance training: a hospital experience, Hacettepe University Journal of the Faculty of Pharmacy $2010 ; 30$ (1): 25-40

25. Inman WH . Attitudes to adverse drug-reaction reporting . Br J Clin Pharmacol 1996;41(5):434-5

26. Figueiras A, Herdeiro MT, Polónia J, Gestal-Otero JJ . An educational intervention to improve physician reporting of adverse drug reactions: a cluster-randomized controlled trial . JAMA 2006 ;296(9):1086-1093

27. Sott HD, Thacher-Renshaw A, Rosenbaun SE, Waters WJ Jr, Green M, Andrews LJ, Faich GA: Physician reporting of adverse drug reactions: results of the Rhode Island Adverse drug reaction reporting project. JAMA 1990 ; 263 (13):1785-1788 